[0212-7199 (2005) 22: 10; pp 473-477] ANALES DE MEDICINA INTERNA Copyright (C) 2005 ARAN EDICIONES, S.L.

An. Med INTERna (Madrid) Vol. 22, N. ${ }^{\circ} 10$, pp. $473-477,2005$

\title{
Encefalitis herpética en adultos: 23 casos
}

\author{
F. J. BURÓN MEDIAVILLA, J. C. RODRÍGUEZ BORREGAN, E. MIÑAMBRES, \\ C. GONZÁLEZ FERNÁNDEZ, A. GONZÁLEZ CASTRO, M. S. HOLANDA PEÑA, \\ A. QUESADA SUESCUN
}

Servicio de Medicina Intensiva. Hospital Universitario Marqués de Valdecilla. Santander

HERPETIC ENCEPHALITIS IN ADULTS: 23 CASES

\section{RESUMEN}

Objetivo: Estudiar la presentación clínica, diagnóstico, tratamiento y pronóstico de la encefalitis herpética en nuestro medio.

Material y método: Estudio retrospectivo de los pacientes mayores de 15 años que ingresaron en nuestro hospital por encefalitis herpética en los últimos 12 años.

Resultados: Se incluyeron 23 pacientes, 14 varones y 9 mujeres. La edad media era de 52,30 $\pm 18,64$ años (rango 18-84). La estancia media en el hospital fue de 26,74 \pm 15,41 días (rango 5-64). Ingresaron en UCI 11 pacientes, requiriendo 9 ventilación mecánica. Los hallazgos clínicos más habituales fueron la alteración del nivel de conciencia y la fiebre. La pleocitosis linfocitaria fue el hallazgo más frecuente en el líquido cefalorraquídeo. Se encontraron lesiones temporales por tomografía en 14 enfermos $(61 \%)$. Fallecieron 4 pacientes, quedando asintomáticos o con mínimas secuelas 7 y 12 desarrollaron secuelas incapacitantes.

Conclusiones: La encefalitis herpética es una enfermedad poco frecuente. El tratamiento de elección es el aciclovir endovenoso y el uso de corticoides es controvertido. El retraso en el inicio del tratamiento empeora el pronóstico. Menos de un tercio de los pacientes consiguen la independencia funcional al alta.

PALABRAS CLAVE: Encefalitis herpética. Adulto. Aciclovir. Virus herpes.

\begin{abstract}
Objective: To study the clinical presentation, diagnosis, treatment and prognosis of the herpetic encephalitis in our environment.

Material and method: During the past 12 years, 23 adults (age $>15$ years) were treated for herpetic encephalitis in our centre.

Results: There were 14 males and 9 females. Ages ranged from 18 to 84 years (mean, 52,30 $\pm 18,64$ years). The hospital stay ranged from 5 to 64 days (mean, 26,74 \pm 15,41 days). Eleven patients were managed in the intensive care unit and nine patients required mechanical ventilation. The most frecuent clinical features they were the level of conscience decrease and fever. The lymphocytic pleiocytosis was the most frequent discovery in cerebrospinal fluid. The temporal lobe lesions in the computed tomography scan appeared in 14 patients (61\%). Four patients died, seven patients were asymptomatic or with minimum sequels and twelve patients developed they were disabled.

Conclusions: The herpetic encephalitis is on uncommon illness. Intravenous acyclovir is recommended treatment and the corticosteroids use is controverted. The delay in the treatment beginning worsens the prognosis. Less than a third of the patients they achieve the functional independence to discharge hospital.
\end{abstract}

KEY WORDS: Herpetic encephalitis. Adult. Acyclovir. Herpes virus.

Burón Mediavilla FJ, Rodríguez Borregan JC, Miñambres E, González Fernández C, González Castro A, Holanda Peña MS, Quesada Suescun A. Encefalitis herpética en adultos: 23 casos. An Med Interna (Madrid) 2005; 22: 473-477.

\section{INTRODUCCIÓN}

El virus del herpes simple es ubicuo en humanos. Pertenece a la familia herpesviridae, todos ellos virus $\mathrm{ADN}$ de doble cadena. Dentro de esta familia, los virus que con mayor frecuencia causan enfermedades en el hombre incluyen: el virus herpes simple tipo 1 y 2 (VHS 1 y VHS 2), el virus varicelazoster (V-Z), el virus de Ebstein-Barr (E-B) y el citomegalovirus (CMV). Además de la producción de cuadros infecciosos, se les atribuye cierta capacidad carcinogénica (1).

La enfermedad primaria en la mayoría de las personas es médicamente imperceptible, pero va acompañada de la producción de anticuerpos y conlleva el estado de portador.
Las manifestaciones clínicas y el curso de la infección va a depender de la estructura anatómica afectada, la edad y el estado inmunológico del huésped, así como del tipo antigénico del virus (2). Microbiológicamente se pueden distinguir dos tipos de VHS, cada uno de ellos presenta unas expresiones clínicas características aunque no específicas. Así, el VHS tipo 1 puede ocasionar gingivoestomatitis herpética aguda, eccema herpético, queratoconjuntivitis, herpes labial y encefalitis; y el VHS tipo 2 herpes genital y herpes neonatal $(1,2)$.

Por tanto, el VHS tiene un amplio espectro de formas clínicas de presentación, siendo la más frecuente la afectación mucocutánea, y la más grave la encefalitis. 


\section{MATERIAL Y MÉTODOS}

Estudio retrospectivo descriptivo de los pacientes mayores de 15 años que ingresaron en nuestro hospital y se les diagnosticó de encefalitis herpética entre el 1 de enero de 1992 y el 31 de diciembre de 2003. Se obtuvieron los siguientes datos: edad, sexo, días de estancia en el hospital y en cuidados intensivos, antecedentes personales, días de intubación, clínica prehospitalaria y al ingreso, bioquímica de líquido cefalorraquídeo (LCR), serología y cultivo en sangre y LCR, proteína $\mathrm{C}$ reactiva (PCR) en $\mathrm{LCR}$, pruebas de imagen, electroencefalografía, procedimientos neuroquirúrgicos, tratamiento, reactivaciones, secuelas al alta hospitalaria y resultados de estudio necrópsico.

\section{RESULTADOS}

Se incluyeron 23 pacientes, 14 varones y 9 mujeres. La edad media fue de 52,30 $\pm 18,64$ años (rango 18-84), siendo por sexos 49,57 $\pm 17,80$ años en los varones y $56,55 \pm 20,17$ años en las mujeres. La incidencia fue de 3,83 casos/ 1.000 .000 y año.

Como antecedentes destacaron: alcoholismo (21,73\%), VIH $(8,69 \%)$, diabetes mellitus $(8,69 \%)$, transplante de órgano sólido $(8,69 \%)$ y cáncer $(4,34 \%)$.

La estancia media en el hospital fue de 26,74 \pm 15,41 días (rango 5-64). Ingresaron en UCI 11 pacientes, requiriendo 9 ventilación mecánica durante 9,62 \pm 4,1 días de media (rango 2-14).

Desde el comienzo de los síntomas hasta el ingreso transcurrieron 4,38 \pm 4,35 días de media (rango 1-20), 2 de los pacientes la desarrollaron estando ingresados en el hospital. La sintomatología de inicio más habitual se presenta en la tabla I, siendo menos frecuentes las alteraciones del comportamiento y las mialgias con dos casos cada una de ellas; y el dolor cervical, petequias, alucinaciones olfatorias o síntomas respiratorios con un caso. Los hallazgos clínicos encontrados con más frecuencia al acudir a urgencias se muestran en la tabla II. Un caso tuvo una presentación atípica, manifestándose como una meningoencefalitis fulminante con petequias simulando una etiología bacteriana.

Se realizó punción lumbar en 20 pacientes, siendo la pleocitosis linfocitaria con hiperproteinorraquia el hallazgo en 17 (85\%), en 2 no había celularidad y 1 tenía pleocitosis de predominio polimorfonuclear. La serología Ig G positiva para virus del grupo herpes en sangre fue de un $60,86 \%$ y en LCR $30 \%$, únicamente apareció serología Ig M positiva para VHS

\section{TABLA I}

PRESENTACIÓN CLÍNICA

\begin{tabular}{ll}
\hline Fiebre & $71 \%$ \\
Alteración de nivel de conciencia & $48 \%$ \\
Cefalea & $38 \%$ \\
Náuseas y vómitos & $29 \%$ \\
Malestar & $24 \%$ \\
Afasia & $19 \%$ \\
Convulsiones & $14 \%$ \\
Mareos & $14 \%$ \\
Trastornos motores & $14 \%$ \\
\hline
\end{tabular}

\section{TABLA II}

HALLAZGOS CLÍNICOS EN URGENCIAS

\begin{tabular}{lr}
\hline Alteración de nivel de conciencia & $74 \%$ \\
Fiebre & $48 \%$ \\
Signos meníngeos & $38 \%$ \\
Focalidad neurológica & $35 \%$ \\
Afasia & $35 \%$ \\
Convulsiones & $9 \%$ \\
Trastornos psiquiátricos & $9 \%$ \\
\hline
\end{tabular}

en un paciente (5\%). La PCR se llevó a cabo en tres enfermos, siendo positiva para herpes tipo I en uno y negativa en dos. Sólo un paciente presentó cultivo positivo débil para virus herpes.

Los hallazgos en la tomografía computerizada (TC) craneal fueron: normalidad en 6 enfermos $(26,08 \%)$, lesiones en áreas temporales izquierdas en $6(26,08 \%)$, temporales derechas en $5(21,73 \%)$ lesiones inespecíficas en $3(13,04 \%)$, y bihemisféricas en $3(13,04 \%)$. Se realizó resonancia magnética nuclear (RMN) en 7 casos, en uno no se observó la alteración que sí aparecía en el TC y en los otros 6 se confirmaron los hallazgos encontrados en el TC. El electroencefalograma (EEG) presentaba hallazgos muy variados: trastornos irritativos de tipo focal en $6(26,08 \%)$, afectación corticosubcortical difusa de intensidad moderada en 5 pacientes $(21,73 \%)$, complejos pseudoperiódicos con afectación corticosubcortical difusa de intensidad moderada en 2 casos $(8,69 \%)$, complejos pseudoperiódicos con afectación corticosubcortical difusa de intensidad moderada y trastornos irritativos focales en 2 casos $(8,69 \%)$, complejos pseudoperiódicos y trastornos focales en 2 casos $(8,69 \%)$, complejos pseudoperiódicos en 1 caso $(4,34 \%)$, complejos periódicos con afectación corticosubcortical difusa de intensidad moderada en 1 caso $(4,34 \%)$, enlentecimiento difuso a en área temporal en 1 caso (4,34\%), trastornos irritativos difusos en 1 caso $(4,34 \%)$, fue normal en 1 caso $(4,34 \%)$ y en otro caso $(4,34 \%)$ se realizó cuando presentaba signos clínicos de muerte encefálica que fue confirmada con el EEG. La tomografía de emisión de positrones se efectuó en 3 casos, en uno no se encontraron datos de significación patológica (como ocurría en el TC y el EEG), y en los otros 2 intensa hipercaptación patológica a nivel de lóbulo temporal izquierdo, al alta uno presentaba disfasia mixta y el otro alteraciones de memoria.

Todos los pacientes recibieron aciclovir endovenoso, excepto el que tuvo la presentación atípica y fulminante que se diagnosticó en la necropsia, durante 15,09 \pm 7,11 días de media (rango 5-36). Los fallecidos presentaban una media de 8,66 \pm 10 días desde el comienzo de los síntomas hasta el inicio del tratamiento, mientras que los pacientes que al alta se fueron asintomáticos o con secuelas estuvieron $4 \pm 3,91$ y $4,33 \pm 2,57$ días respectivamente. Recibieron corticoides el $43,47 \%$. Los fármacos antiepilépticos fueron administrados como tratamiento en el 39,13\% y de forma profiláctica en el $30,43 \%$. Se colocó un sensor de presión intracraneal (PIC) en tres pacientes, uno durante 10 días con cifras normales, otro durante 5 días con PIC elevadas $\left(>20 \mathrm{~cm} \mathrm{H}_{2} \mathrm{O}\right)$ un total de 12 horas y el tercero durante 11 días con PIC altas 50 horas, siendo este último el que más secuelas al alta presentó. 
Fallecieron 4 pacientes, uno de ellos a los 3 días del alta. Se fueron asintomáticos o con mínimas secuelas 7 y 12 con secuelas incapacitantes (Fig. 1).

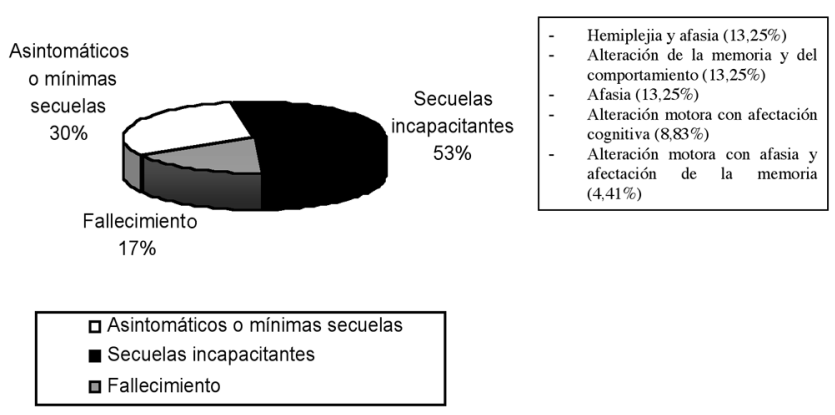

Fig. 1. Resultados clínicos al alta.

Uno de los pacientes sufrió una recaída, había recibido tratamiento con aciclovir durante 20 días y al alta presentaba como secuela una disfasia mixta de predominio sensitivo. Tres días después del alta comenzó con cefalea frontal opresiva, febrícula, náuseas y aumento de su disfasia. En el LCR presentó pleocitosis linfocitaria con hiperproteinorraquia y serología IgM positiva. En la RNM presentó captación de contraste lo que indicaba cierto grado de actividad como ocurrió en la tomografía de emisión de positrones (SPECT). Recibió otros 10 días de tratamiento con aciclovir, recuperando su estado basal.

\section{DISCUSIÓN}

La encefalitis herpética $(\mathrm{EH})$ es la causa más frecuente de encefalitis aguda en los países occidentales $(3,4)$. No existen diferencias de sexo, ni tampoco en cuanto a la edad, aunque se ha descrito una aparición bimodal en torno a los 20 y los 50 años (5). Su incidencia es de 1-4 casos/1.000.000 habitantes y año (6). El 90\% de las EH en adultos y en niños mayores tienen como agente causal el VHS 1 (7). En los últimos años están apareciendo casos de encefalitis producidos por otros herpesvirus, como el tipo 6, especialmente en huéspedes con inmunosupresión postransplante $(8,9)$, siendo esporádicos los casos publicados de afectación en personas inmunocompetentes $(10,11)$. Su importancia radica en el tratamiento, siendo ganciclovir y foscarnet solos o en combinación los antivirales de elección dada su buena actividad in vitro, no así el aciclovir que únicamente a dosis elevadas parece tener alguna actividad frente al herpes 6 (9).

En nuestra serie la incidencia es similar a la descrita en la literatura. Encontramos un ligero predominio en varones. La edad se situó en torno a los 50 años, si bien el rango fue muy amplio, siendo las mujeres las más afectadas en edades más altas.

La patogénesis de la infección es un tema en discusión, se cree que la infección primaria se produce por la migración del virus procedente de las mucosas a través de los tractos nerviosos del nervio olfatorio o el trigémino, lo que explicaría el especial tropismo de este virus por las áreas frontobasales y temporales. En las reactivaciones, se cree que la infección se produce por la presencia del virus de forma latente en el propio tejido cerebral o bien se produce una reactivación del virus a nivel periférico migrando al tejido nervioso desde el bulbo olfatorio o el ganglio del trigémino $(4,12)$.

La presentación clínica más frecuente es la forma aguda, pudiendo existir casos de presentación subaguda. La mayoría de los pacientes presentan clínica que sugiere la afectación de las áreas temporales y/o frontales (13), así las manifestaciones clínicas más habituales incluyen: alteración del nivel de conciencia, fiebre, cefalea, cambios de personalidad, disfasia, convulsiones, hemiparesia y edema de papila (14). El ingreso de los pacientes en una unidad de cuidados intensivos viene determinado por la alteración del nivel de conciencia o la presencia de crisis convulsivas repetidas. También en nuestro caso fue la alteración del nivel de conciencia y la fiebre los hallazgos clínicos iniciales más frecuentes.

En la literatura se describen las llamadas formas atípicas, que incluyen un $20 \%$ de los casos, entre las que destacan: la encefalitis troncoencefálica, encefalitis crónica, encefalitis con disfunción diencefálica o localización occipital. Estas formas de aparición son más frecuentes en pacientes inmunodeprimidos y suelen estar producidas por VHS 2 (15). También están descritas evoluciones hacia hematoma cerebral (16). Únicamente aportamos un caso de presentación atípica, que se manifestó como una meningitis bacteriana con la aparición de petequias en la piel y evolucionó rápidamente hacia la muerte encefálica.

La pleocitosis linfocitaria con hiperproteinorraquia es la anormalidad más frecuente del líquido cefalorraquideo (LCR) (17). Existen numerosas publicaciones que demuestran la validez de la serología para el diagnóstico de la encefalitis herpética, aunque todas ellas parecen estar de acuerdo en que tiene valor como diagnóstico de confirmación tardío, y por tanto su importancia es relativa en una enfermedad donde el diagnóstico precoz es primordial $(18,19)$. La positividad para el cultivo de LCR se estima en $<5 \%$ (12).

Dentro de las pruebas de imagen, la TC presenta lesiones sugestivas en un 50\% (8), muy similar a los resultados de muestra serie $(52,63 \%)$, siendo poco sensible en los primeros días de la enfermedad; parece que la RNM podría jugar un papel en el diagnóstico por imagen más temprano (20,21). La hipercaptación (hiperperfusión) cerebral en el SPECT es un predictor independiente de mal pronóstico, al ser indicativo de inflamación severa en el tejido cerebral (22). Las manifestaciones electroencefalográficos no son específicos aunque pueden ayudar al diagnóstico, pudiendo aparecer complejos periódicos o pseudoperiódicos y/o trastornos irritativos de tipo focal, junto con complejos de ondas lentas.

La biopsia cerebral ha sido históricamente considerado el método gold-standard para el diagnóstico, sin embargo, las complicaciones de esta técnica no eran nada despreciables. Con la aparición de la reacción en cadena de la polimerasa (PCR), técnica de laboratorio rápida y sencilla, y con una alta sensibilidad y especificidad para la demostración de la presencia del virus en LCR avalada por numerosos estudios, se ha desplazado a la biopsia cerebral como método diagnóstico de certeza (23-25). No sólo eso, en últimos estudios se está utilizando esta técnica como monitorización del tratamiento, demostrándose la disminución de ADN viral en LCR a medida que pasan los días de tratamiento $(26,27)$. 
El tratamiento de elección es el aciclovir endovenoso (10 $\mathrm{mg} / \mathrm{kg} / 8 \mathrm{~h}$ ) durante 10-14 días. Algunos autores propugnan que se debe ampliar el tiempo de tratamiento hasta 3 semanas para evitar las recurrencias $(12,28)$. La alternativa al aciclovir es la vidaravina o el foscarnet, este último parece el más indicado en los paciente inmunodeprimidos donde con mayor frecuencia aparecen resistencias al aciclovir (3). La asociación con corticoides es controvertida, los defensores la utilizan con la esperanza de disminuir el edema cerebral por su efecto antiinflamatorio potente, sus detractores propugnan que su acción inmunosupresora favorece la replicación del virus y la diseminación al sistema nervioso (29). Los anticomiciales se utilizan en caso de que aparezcan crisis convulsivas, siendo de elección la fenitoína, no existen datos para utilizarlo de forma profiláctica; incluso algunos autores no los consideran necesarios ya que muchos de los pacientes que los precisarían están ingresados en una UCI y la gran mayoría con medicación sedante con propiedades anticonvulsivantes $(30,31)$. La cirugía descompresiva estaría indicada en aquellos individuos que presentan herniación uncal o aumentos incontrolables de la presión intracraneal (32).

Se estima un porcentaje de recaídas en torno a un 5-10\% (3), generalmente por reactivación del virus achacada a un tiempo de tratamiento insuficiente como ya se ha dicho anteriormente (33).

La mortalidad antes de la aparición de los antivirales era de un $70 \%$, y los supervivientes presentaban graves secuelas. Con la aparición del aciclovir, las tasas de mortalidad se han reducido hasta un $20 \%$ y las secuelas son menos incapacitantes, similar a lo observado en nuestro estudio. Tradicionalmente se decía que la edad > 30 años, el estado de nivel de conciencia (escala de coma de Glasgow <6) y una evolución de la encefalitis $>4$ días sin tratamiento eran determinantes para el pronóstico de la enfermedad $(34,35)$, pero en estudios publicados en los últimos años se llega a la conclusión de que la administración temprana de la terapia antiviral es el único parámetro capaz de modificar el pronóstico de la enfermedad,

\section{Bibliografía}

1. Familia de los herpesvirus. En: Jawetz E, Melnick JL, Adelberg EA. Microbiología Clínica. 12ª Edición. El Manual Moderno, S.A.; 1989, p. 522-532.

2. Corey L. Herpes Simplex Viruses. In: Braunwald E, Fauci AS, Kasper DL, Hauser SL, Longo DL, and Jameson L. Harrison's Principles of Internal Medicine. 15 th Edition. McGraw Hill; 2001.

3. Hinson VK, Tyor WR. Update on viral encephalitis. Curr Opin Neurol 2001; 14: 369-374.

4. Whitley RJ, Lakeman F. Herpes simplex virus infections of the central nervous system: Therapeutic and diagnostic considerations. Clin Infect Dis 1995; 20: 414-420.

5. Whitley RJ. Herpes virus simplex. In: Sheld WM, Whitley RJ, Durack DT. Infections of the central nervous system. 2nd. Edition. Philadelphia: Lippincott-Raven, 1997.

6. Spuler A, Blaszyk H, Parisi JE, Davis DH. Herpes simplex encephalitis after brain surgery: case report and review of the literature. J Neurol Neurosurg Psychiatry 1999; 67: 239-242.

7. Kennedy PGE, Chaudhuri A. Herpes simplex encephalitis. J Neurol Neurosurg Psychiatry 2002; 73: 237-238.

8. Ward KN. Human herpesviruses-6 and -7 infections. Curr Opin Infect Dis 2005; 18: 247-52.

9. Benito N, Moreno A, Pumarola T, Marcos MA. Virus del herpes huma- tanto en mortalidad como en secuelas $(35,36)$. Nuestros datos parecen corroborarlo en cuanto a la mortalidad, no así en las secuelas, donde el tiempo de instauración del tratamiento fue similar.

Clásicamente se hablaba de secuelas neurológicas muy severas en el 40-60\% de los supervivientes. Con la aparición de la terapia antiviral estos porcentajes se reducen a un $18-42 \%$, y de ellos la mayor parte presentan secuelas que no son tan graves y les permiten cierto grado de independencia. Principalmente se describen secuelas de la esfera cognitiva y del comportamiento. En una publicación reciente sobre seguimiento de los pacientes con secuelas cognitivas por esta enfermedad se llega a la conclusión de que con el paso del tiempo se recuperan parte de las funciones intelectuales pérdidas en la fase aguda (37). Otro estudio pone de manifiesto que en la actualidad las secuelas a largo plazo son menos graves, expone que un $30 \%$ de los pacientes estudiados fallecieron o tuvieron secuelas neurológicas severas y el resto consiguió una independencia para ciertos aspectos de su vida habitual, aunque en la gran mayoría persistieron signos y síntomas neurológicos, siendo los síntomas más frecuentes la alteración de la memoria, seguido de alteraciones de la personalidad y del comportamiento, y la epilepsia; y los signos más comunes son la alteración de la memoria reciente, la anosmia y la disfasia (34).

\section{CONCLUSIONES}

La encefalitis herpética es una enfermedad poco frecuente. La sospecha clínica elevada es suficiente para iniciar el tratamiento, siendo el aciclovir el fármaco de elección. El uso de corticoides es controvertido. El retraso en el comienzo del tratamiento parece influir negativamente en el pronóstico. En menos de la tercera parte de los pacientes se consigue la independencia funcional al alta. no tipo 6 y tipo 7 en receptors de trasplantes. Enferm Infecc Microbiol Clin 2003; 21: 424-32.

10. Córdoba López A, Bueno Álvarez-Arenas I, Monterrubio Villar J, Sánchez Castanon J. Meningoencefalitis por virus herpes simple tipo 6 en adulto inmunocompetente. An Med Interna (Madrid) 2004; 21: 201.

11. Cutrin Prieto C, Batalla Eiras A, Pato Salgado M. Meningoencefalitis por virus herpes tipo 6 en paciente anciano con Alzheimer. An Med Interna (Madrid) 2005; 22: 299-300.

12. Levitz RE. Herpes simplex encephalitis: A review. Heart Lung 1998; 27: 209-212.

13. Johnson RT. Acute encephalitis. Clin Infect Dis 1996; 23: 219-226.

14. Roos KL. Central nervous system infections. Neurol Clin 1999; 17: 453-482.

15. García Barragan N, Rodríguez Espinós N, Fernández Ruiz LC, Marjuán J. Encefalitis herpética de presentación atípica. Rev Neurol 2000; 30: 441-444.

16. Politei JM, Demey I, Pagano MA. Hematoma cerebral en el curso de una encefalitis herpética. Rev Neurol 2003; 36: 636-639.

17. Steiner I, Biran I. Herpes simplex encephalitis. Current Treatment Options in Infectious Diseases 2002; 4: 491-499.

18. Sauerbrei A, Wutzler P. Laboratory diagnosis of central nervous system infections caused by herpesviruses. J Clin Virol 2002; 25 (Supl. 1): S45-51. 
19. Ceroni M, Camana C, Franciotta DM, Bolelli G, Revello MG, Gerna G, Savoldi F. Serum and cerebrospinal herpes simples virus type $1 \mathrm{immu-}$ noglobulin $\mathrm{G}$ and $\mathrm{M}$ titers in four cases of herpes simplex encephalitis. Boll Soc Ital Biol Sper 1990; 66: 1215-1222.

20. Schroth G, Gawehn J, Thron A, Vallbracht A, Voigt K. Early diagnosis of herpes simplex encephalitis by MRI. Neurology 1987; 37: 179-183.

21. Gasecki AP, Steg RE. Correlation of early MRI with CT scan, EEG, and CSF: analyses in a case of biopsy-proven herpes simplex encephalitis. Eur Neurol 1991; 31: 372-375

22. Launes $\mathbf{J}$ et al. Unilateral hyperfusion in brain-perfusion SPECT predicts poor prognosis in acute encephalitis. Neurology 1997; 48: 1347-1351.

23. Muñoz Almagro C, González Cuevas A, Cambra FJ, Juncosa T, Mira A, Latorre C. Diagnóstico rápido de la meningoencefalitis herpética mediante PCR. Enferm Infecc Microbiol Clin 2002; 20: 110-112.

24. Mitchell PS, et al. Laboratory diagnosis of central nervous system infections with herpes simplex virus by PCR performed with cerebrospinal fluid specimens. J Clin Microbiol 1997; 35: 2873-2877.

25. Caparrós Lefebvre et al. Value of gene amplification of herpesviruses in the diagnosis and treatment of acute viral encephalitis. Rev Neurol (París) 1995; 151: 124-128.

26. Murcia J, Merino E, Boix V, Portilla J. Tratamiento prolongado de la encefalitis herpética con aciclovir. El papel de la reacción en cadena de la polimerasa en el líquido cefalorraquídeo. Med Clin (Barc) 2002; 118: 519.

27. Koskiniemi M, Piiparinen H, Mannonen L, Rantalaiho T, Vaheri A. Herpes encephalitis is a disease of middle aged and elderly people: polymerase chain reaction for detection of herpes simplex virus in the CSF of 516 patients with encephalitis. The study Group. J Neurol Neu- rosurg Psychiatry 1996; 60: 174-178.

28. Cepelowicz J, Tunkel AR. Viral encephalitis. Current Treatment Options in Infectious Diseases 2003; 5: 11-19.

29. Thompson KA, Blessing W, Wesselingh SL. Herpes simplex replication and dissemination is not increased by corticosteroid treatment in a rat model of focal herpes encephalitis. J Neurovirol 2000; 6: 2532.

30. Ziai WC, Geocadin RG. Central nervous system infections: A critical care approach. Curr Neurol Neurosci Rep 2001; 1: 577-586.

31. Schmutzhard E. Viral infections of the CNS with special emphasis on herpes simplex infections. J Neurol 2001; 248: 469-477.

32. Yan HJ. Herpes simplex encephalitis: the role of surgical decompression. Surg Neurol 2002; 57: 20-24.

33. Ito Y, Kimura H, Yabuta Y et al. Exacerbation of herpes simples encephalitis after successful treatment with acyclovir. Clin Infect Dis 2000; 30: $185-187$.

34. McGrath M, Anderson NE, Croxon MC, Powell KF. Herpes simplex encephalitis treated with acyclovir: diagnosis and long term outcome. J Neurol Neurosurg Psychiatry 1997; 63: 321-326.

35. Raschilas F et al. Outcome of and prognostic factors for herpes simplex encephalitis in adult patients: Results of a multicenter study. Clin Infect Dis 2002; 35: 254-260.

36. Kaplan CP, Bain KP. Cognitive outcome after emergent treatment of acute herpes simplex encephalitis with acyclovir. Brain Inj 1999; 13: 935-941.

37. Hokkanen L, Launes J. Cognitive recovery instead of decline after acute encephalitis: a prospective follow up study. J Neurol Neurosurg Psychiatry $1997 ; 63: 222-7$. 